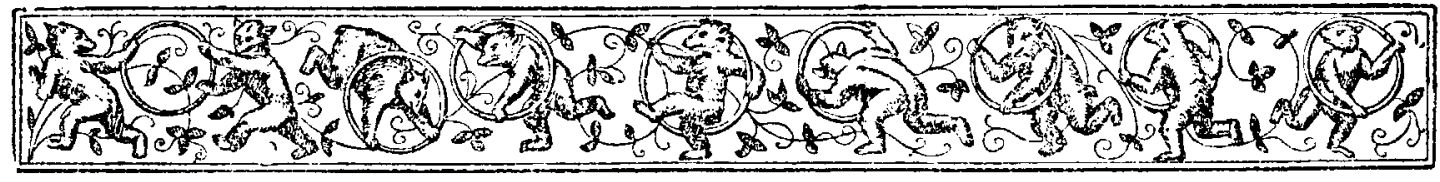

\title{
DE SCHILDER GERRIT VAN HEES
}

DOOR

\author{
A. B R E D I U S.
}

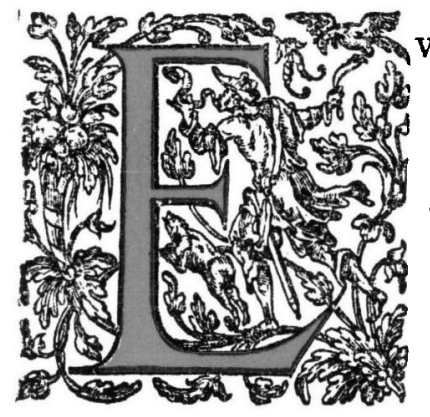

VENALS zich om REMBRANDT een drom van leerlingen, tijdgenooten en navolgers schaart, die in hunne beste werken hun voorbeeld dikwijls zeer nabij komen, heeft JACOB VAN RUISDAEL een aanzienlijke groep van navolgers gehad, die hem reeds vroeg nastreefden en wier werk soms zeer sterk op het zijne gelijkt. Ik herinner aan de landschappen van Gullliam Du Bois, de boschgexichten van JILlis Rombouts, den ouden JAN VAN DER MEER, (bijv. het stuk in het Mauritshuis) enkele landschappen van ROELOF VAN VRIES, VER schilders uit deze groep is GERRIT VAN HEEs.

I88I schreef ik in ,de Nederlandsche Kunstbode":

,Toen ik de merkwaardige verzameling van den Heer Houck, Notaris te "Deventer, voor het eerst bezocht, trok een groot, somber ${ }^{1}$ ) landschap bizonder „mijn aandacht. In een bosch zien wij een boerenhut; de rook stijgt kalm op uit "den schoorsteen. (En verdere beschrijving - de reproductie, hierbij gevoegd, "maakt die hier overbodig). De schilderwijze herinnert aan R. VAN VRIES doch „ook in sommige opzichten aan JACOB VAN RUISDAEL. Het stuk is zeer vet, breed, „warm geschilderd; een geniaal meester moet dit werk uitgevoerd hebben. "Gemerkt: G. van Hees 1650. Op paneel, hoog ca. 76 cM. breed ca. 106 cM."

1) Na de herstelling van dit stuk is de somberbeid grootendeels geweken. 
Ik vond toen niets anders over hem dan zijn naam bij VAN DER WILLIGEN in zijn "Peintres de Haarlem" op een lijstje der geheel onbekende schilders, die voor I702 overleden waren.

De schilderij, die ik toen aan hem meende te moeten toeschrijven ir de Collectie Amsingh (nu in de Kunsthalle) te Hamburg, is toch niet van hem en wel degelijk een zeer vroeg werk van JACOB VAN RUISDAEL, wiens handteekening het draagt en het jaartal 1647. De koebeesten op dat stuk zijn van de hand van BERCHEM.

Gelukkig hangt thans door de goede zorgen van Dr. Hotstede de Groot de vaN HeEs uit Deventer in het Gemeente Museum van Haarlem. De afbeelding er van geeft helaas de fijne grijze wolken niet terug, en ook op de andere reproducties zijn die bijna verdwenen. Een tweede G. VAN HEES I665 gemerkt stuk vond ik als C. DECKER gecatalogiseerd, in het Museum te Rennes. (No. 87 van den Catalogus, h. I.08, br. I.5 I). De figuurtjes lijken mij bijna toe er door ADR. VAN OSTADE in geschilderd te zijn. De hierbij gevoegde afbeelding maakt een beschrijving overbodig.

Bepaald door VAN HEEs geschilderd is een landschap in het Museum te Lille (No. 266 van den Catalogus, aan eenen Simon Du BoIs (Guiliam was bedoeld!) toegeschreven. „Dans un terrain rempli de trouées sablonneuses et de „touffes de bruyères, diverses habitations se cachent au milieu d'un massif d'arbres, "Ciel couvert de gros nuages gris. H. I.13, br. I.OI,

Een vierde stuk, zonder eenigen twijfel van VAN HEEs bevindt zich thans (uit Engeland komende) in de groote Collectie van Comm. Rath Cremer, te Dortmund. Het is bizonder poëtisch en het geval zeer gelukkig gekozen. Ook de Ruisdael'sche belichting geeft er een groote aantrekkelijkheid aan. Onze afbeelding geeft er maar een gebrekkig denkbeeld van. Doek, h. o. 36, breed 0.42 .

Een vijfde stuk werd door Dr. HofSTEDE DE GROOT zoo gedoopt. Het droeg reeds allerhande namen en een twijtelachtige handteekening van J. vAN RUISDAEL, Het is de bekende "Landschaft mit den Planken" in de verzameling de K.K. Akademie der bildenden Künste" te Weenen. Ook hier is het schilderachtige geval gelukkig gekozen.

Al deze stukken lijken zeer veel in behandeling en kleur op het vroegste en vroege werk van JACOB VAN RUISDAEL. De vette penseelsbehandeling, soms wat blauwachtig groen in het gebladerte, de manier waarop dat geschilderd is, de grijze, teêre wolken, die een mooi spel van het zonnelicht veroorloven, dit alles doet aan de RUISDAEL's van \pm I650 en er vóór, denken.

Ik ben thans in staat iets meer over dezen zeldzamen meester te vertellen. Hij zal omstreeks 1625, dus zoowat gelijktijdig met RUISDAEL, geboren zijn. 


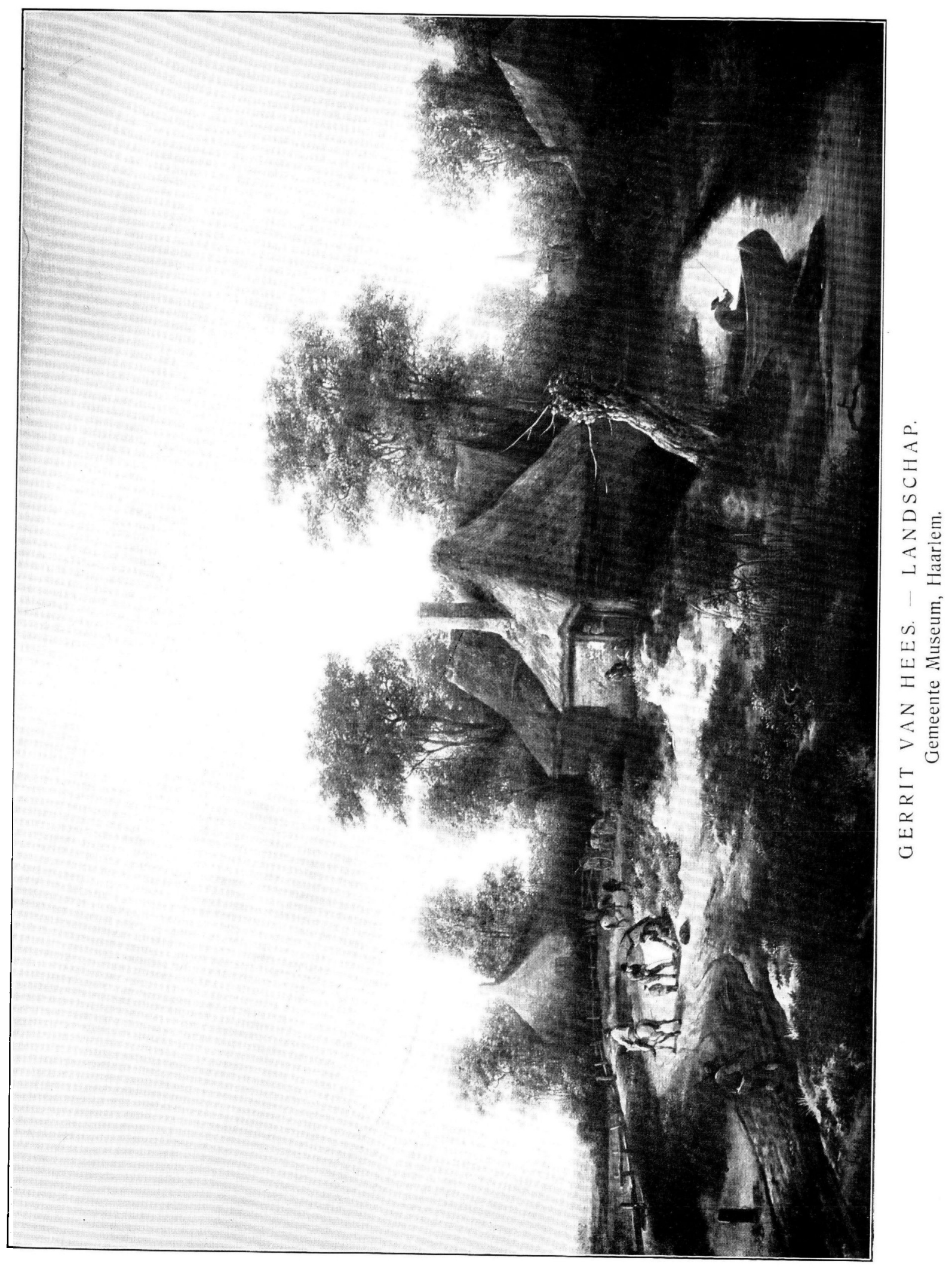





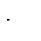




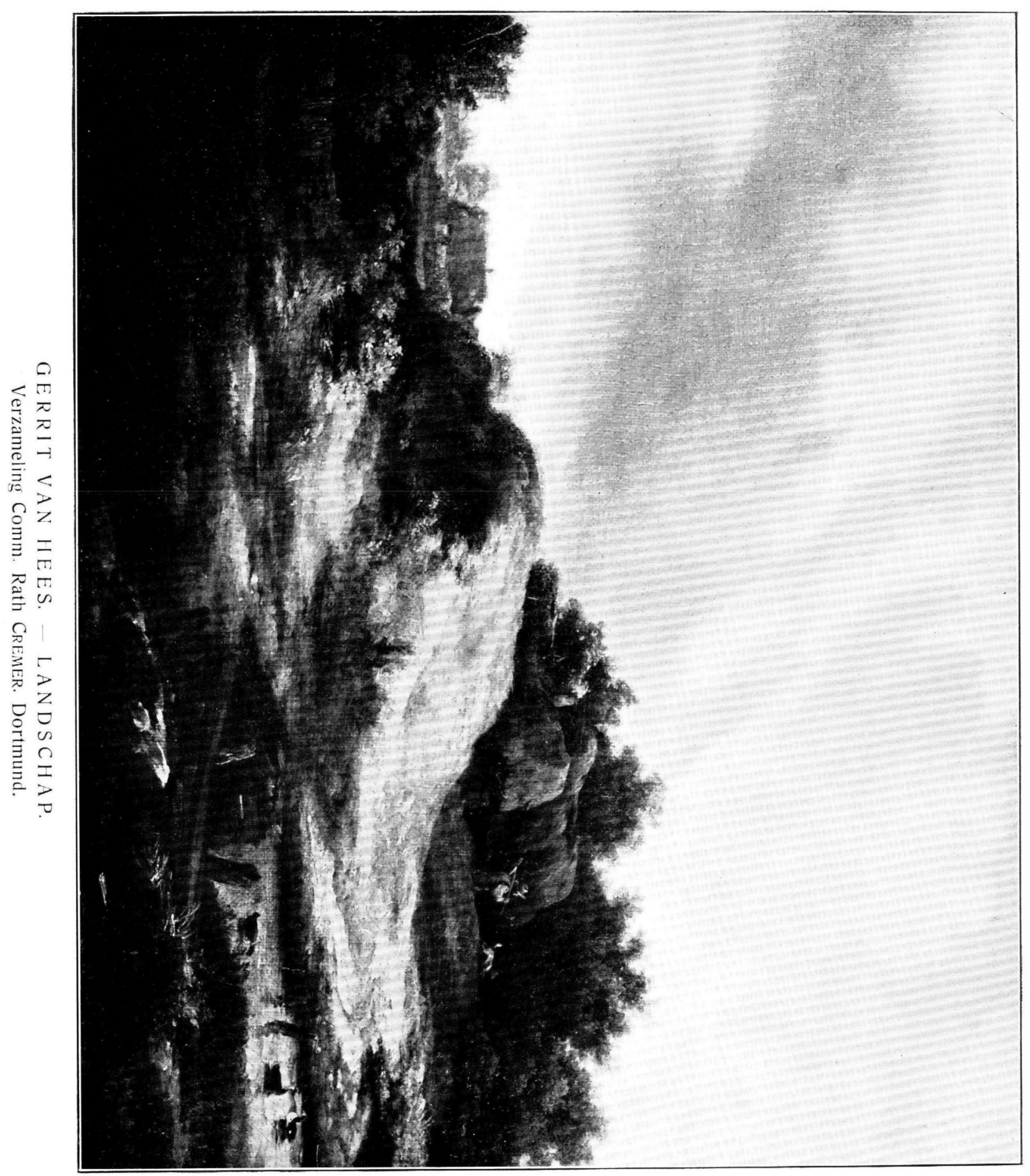

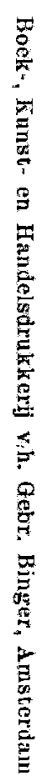


Het is hem zeker ook niet voorspoedig gegaan, en ik vrees, dat hij daarom zoo weinig geschilderd heeft. $\mathrm{Hij}$ gaf heel goedkoope lessen, en heeft wellicht om den broode nog een ander vak er bij beoefend. Bij zijn overlijden wordt hij niet „schilder" genoemd, maar zijn armelijk boeltje duidt er wel op, dat hij nog schilderde.

Hier volge het weinige wat ik over hem in de archieven mocht vinden. In de rekeningen (doodschulden) van juffr. ANNA BORST, wed. van GERBRANT Borst, 23 Sept. 1663 te Haarlem opgemaakt:

Noch comt GerRit van HeES van 2 maenden leergelt. . . . $f$ 8.-

Deze dame bezat o.a. een Cruijs van GeErTIE vaN Sr JAN ,'t welck schoone es"; het was in onderpand gegeven. Floris van Schooten en SAlomon dE BRAY, beide schilders, waren geld schuldig (voor bier). ${ }^{1}$ )

Uit een Acte van 6 Jan. I660 moet ik opmaken dat vaN HEES gehuwd was met eene dochter van CoRnElis HARCX, (hier HARCKX geschreven). ${ }^{2}$ )

23 Sept. I670 makkt d'eersame GERRIT vaN HEES, burger deser Stadt (Haarlem) sieckelyck te bedde leggende, sijn Testament voor Not. W. KITTENSteyn. CoRnelis VAN CAMPen $f$ 50.-, zijn zwager Willem Leendertsz. $f$ 25.-, EverT ClaEsz VAN VEEN, (schoenmaker) syn hospes, daer hy tegenwoordich bij woont $f 25 .-$ en het volle jaer huur als hy sterft. Voorts erven zijne familieleden, de kinderen van twee halve zusters. Hij teekent

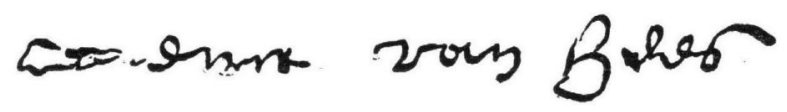

De Heer GonneT vond zijn begrafenis datum, 6 Oct. 1670; hij werd in St. Bavo ter aarde çesteld. Den volgenden dag verscheen de Notaris Kittensteyn in de woning van den schoenmaker, om op te schrijven, wat er van den schilder nog aanwezig was.

CoRnelis van CAMPEN is executeur.

Hij bezat nog een huis en erve in de Molstraat, naast de brouwerij van de Fortuyn.

Voorts wat kleeren, mantels, onderkleeren, ,van weynich waerde" 2 paar koussen, eenige printen en teyckeninghen.

een stuck schilderij

drie dos, sonder lyst

een taeffereel

een esel, met een steen om verruw te wryven.

1) Prot. Not. M. De Keijser, Haarlem.

2) $n \pi$ W. KittensteYN. " 
Er waren nog schulden voor kleeren, oppassen gedurende de ziekte, en de Notaris. Slechts zelden vindt men schilderijen van vaN HEES vermeld. In den kostbaren inboedel van den Amsterdamschen burgemeester NICOLAES VAN BAMBEECK 22 Febr. 1723 opgemaakt - hij had een kunstkabinet! - is, als No 30 vermeld: een landschapje van GERRIT VAN HEES. 1673 geeft de schilder LAMBERT HENDRICKSZ VAN DER STRAATEN te Haarlem met vele andere schilderijen, (o.a. ruim 30 stukken van hem zelf!) in onderpand: een lantschapje van GERRIT vaN HEEs. Bij GERARD HOET is geen enkel stuk van hem vermeld.

Lang geheel vergeten, zij GERRIT VAN HEES thans weer herdacht als een onzer zeer goede en sympathieke landschapschilders uit den "gouden eeuw" onzer schilderkunst.

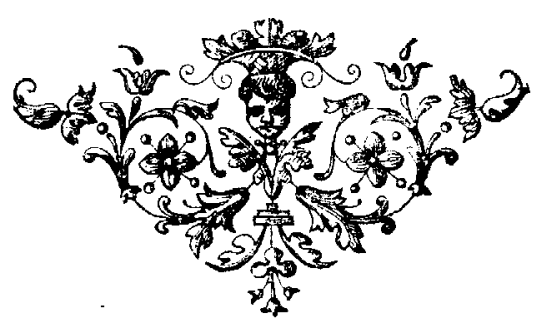




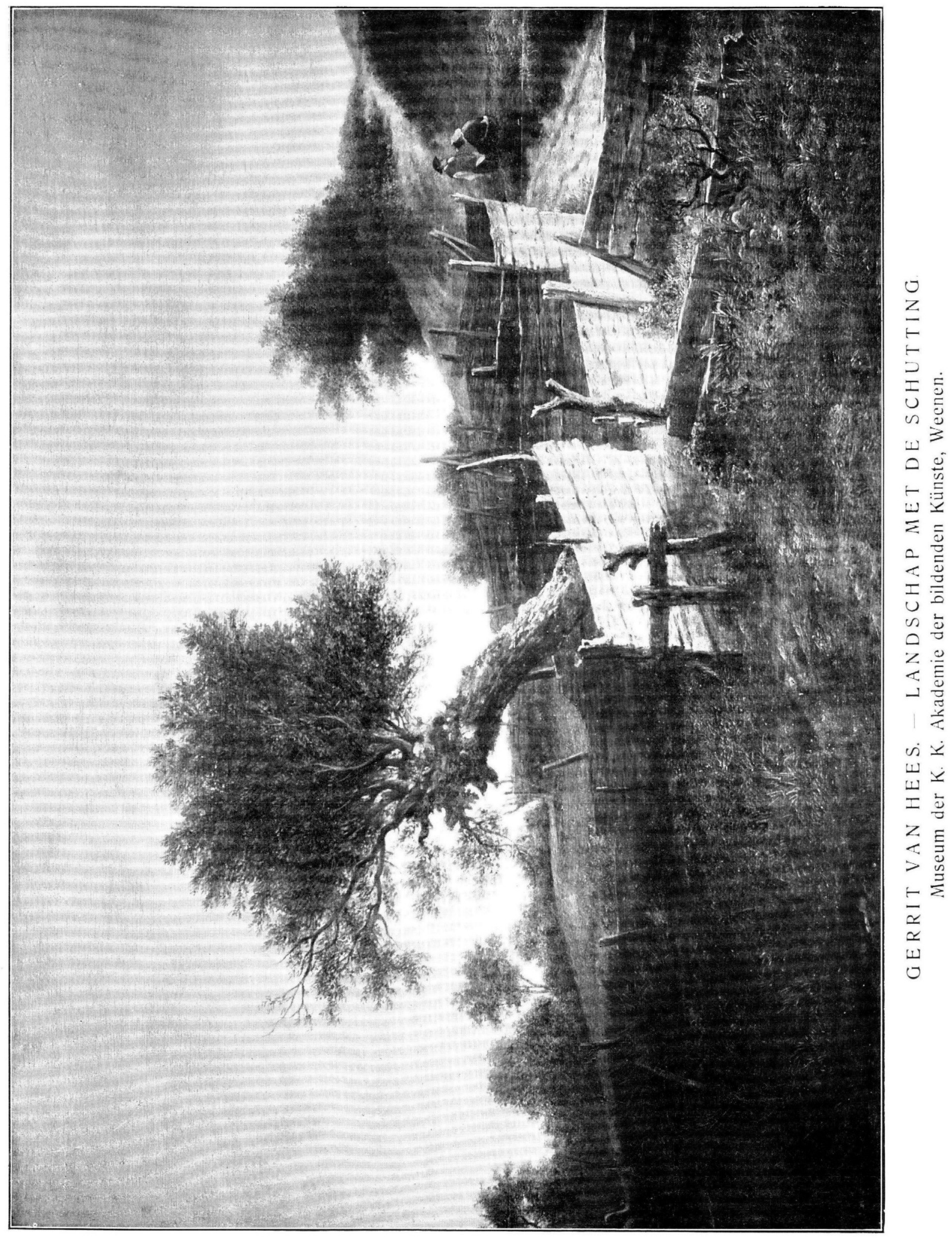

